Original article

\title{
Nurses' attitude towards attendance of nursing students in the clinical setting in Shahrekord in 2015
}

\author{
Neda Parvin ${ }^{1}$, Fatemeh Aliakbari ${ }^{1}$, Leila Rafiee Vardanjani ${ }^{*}$, Narjes Khaton Dadkhah ${ }^{1}$, Leila Mahasti Jouybari ${ }^{3}$
}

(Received: 3 Jul 2016; Accepted: 12 Sep 2016)

\begin{abstract}
Background and Purpose: Attendance of nursing students in clinical settings is an inherent element of nursing education. This study aimed to evaluate the attitudes of nurses toward the attendance of nursing students in clinical settings in Shahrekord, Iran.

Methods: This descriptive study was conducted in Hajar teaching hospital of Shahrekord city, Iran in 2015. Using convenience sampling, 150 eligible nurses were selected for this study. Data were collected using demographic questionnaires and Stagg's attitude scale. In addition, we assessed the viewpoints of nurses regarding the advantages and disadvantages of the attendance of nursing students in clinical environments using two open questions. Data analysis was performed using Chi-square, Student's t-test, and Pearson's correlation-coefficient.

Results: Negative attitude toward the attendance of nursing students in clinical settings was observed in $82 \%$ of the participants. Moreover, $80.7 \%$ of the nurses believed that nursing students are not able to acquire sufficient clinical experiences in clinical environments. On the other hand, no significant correlation was observed between age, work experience, marital status, and attitude toward the attendance of nursing students in clinical settings $(P>0.05)$. However, this difference was only significant in terms of the ward of employment $(P=0.004)$, so that nurses engaged in the psychiatric ward had a more positive attitude toward this concept compared to other nurses.

Conclusion: According to the results of this study, special attention must be paid to the clinical education of nurses with regard to their experiences and viewpoints toward improving clinical learning.
\end{abstract}

Keywords: Attitude, Clinical education, Nurse, Student

\section{Introduction}

Clinical experience plays a pivotal role in proper clinical-based nursing education, which affects the quality of learning in nursing students (1). Clinical learning experiences require the interaction of nursing students and their presence in clinical settings (2). Such interactions could simplify or inhibit the learning process in nursing students and impact on their transition to clinical practice $(3,4)$. In a clinical environment, nursing students gain new experiences in terms of professional interactions, communication skills and socialization (5).

Considering the constant interactions of nursing students with nurses, developing a supportive clinical environment is crucial to promoting a sense of belonging in these students (6). A supportive, interpersonal relationship between nursing students and nurses in clinical environments is essential to fostering a beneficial learning environment for nursing students

\footnotetext{
${ }^{1}$ Department of Nursing, School of Nursing, Shahrekord University of Medical Sciences, Shahrekord, Iran

${ }^{2, *}$ Corresponding author: Department of Nursing, School of Nursing, Shahrekord University of Medical Sciences, Shahrekord, Iran. Email: rafiee.leila@yahoo.com

${ }^{3}$ Department of Nursing, School of Nursing, Golestan University of Medical Sciences, Gorgan, Iran
} 
(7). In addition, a positive, constructive relationship between nurses and nursing students could be largely effective in increasing learning efficiency (8).

Positive attitude of nurses toward nursing students is significantly involved in the socialization of these students (9). Furthermore, proper communication of nurses and nursing students could improve the interactions between healthcare centers and universities (9). On the other hand, negative attitude of nurses toward nursing students could adversely affect their education and lead to nursing staff shortage (9).

Few studies have focused on the attitude of Iranian nurses toward the attendance of nursing students in clinical settings. In a study conducted in Ardabil (Iran), the results were indicative of the poor or moderate perception of nurses in this regard (3). Attitude of nurses plays a critical role in improving clinical learning, largely influencing their interactions with nursing students.

This study aimed to evaluate the attitudes of nurses toward the attendance of nursing students in clinical environments.

\section{Materials and Methods}

This descriptive, cross-sectional study was conducted to assess the attitude of nurses toward the attendance of nursing students in clinical settings in 2015. Study population consisted of nurses engaged in different wards of Hajar Hospital, which is a teaching referral center affiliated to Shahrekord University of Medical Sciences, Iran.

Participants were selected from medical, surgical, pediatric, psychiatric, hemodialysis, emergency, and infectious disease sections. Additionally, clinical supervisors and nurses engaged in the cardiac care unit, intensive care unit, neonatal intensive care unit (NICU), and obstetric ward were enrolled in this study. According to prior enquiries, most of the educational programs for nursing students are implemented in the mentioned wards.

In this study, participants were selected via convenience sampling. Out of 250 nurses employed in this hospital, 180 cases were eligible for this study.

Inclusion criteria were employment as a nurse or clinical supervisor, minimum clinical nursing experience of six months, and willingness to participate in the study. Nurses who were students at the time of the study were excluded from further evaluation.

\section{Ethical considerations}

Study protocol was approved by the Ethics Committee of Shahrekord University of Medical Sciences (code: 1393-01-68-2331). Informed consent was obtained from eligible nurses, and participation in the research was voluntary. Moreover, selected nurses were assured of confidentiality terms regarding their personal information.

\section{Data collection}

Data were collected using demographic questionnaires and Stagg's nursing attitude scale. Demographic characteristics included age, gender, ward of employment, and clinical experience.

Stagg's attitude questionnaire consists of 41 items, which are scored based on a five-point Likert scale (Strongly Agree to Strongly Disagree). Subscales of this questionnaire are time, motivation, knowledge, personal issues, professional issues, instructor-student relationship, and background comparison (10).

Stagg's questionnaire of attitude has been translated into Persian by Aghamohammadi-Kalkhoran et al., and the validity of this version has been assessed through back translation. In terms of simplicity, relevance and clarity, validity of this scale has been estimated at $87.3 \%, 80.8 \%$ and $79.42 \%$, respectively. In addition, reliability of this questionnaire has been determined at 89.28\% based on Cronbach's alpha coefficient.

Items in the Persian version of Stagg's attitude questionnaire are scored based on a three-point Likert scale, as follows: Agree (score one), Undecided (score two), and Disagree (score three). Total score is calculated by summing up the obtained scores of each item within a range of 41-123. Scores 41-95 are indicative of negative attitude, while scores 96123 are interpreted as positive attitude (3).

After two weeks, test-retest was applied to evaluate the viewpoints of 15 nurses, and reliability of the questionnaire was determined at $\mathrm{r}=82.2 \%$. Moreover, viewpoints of nurses regarding the advantages and disadvantages of the attendance of nursing students in the clinical environment were 
assessed by two open questions. Another open question was used to propose the strategies for the enhancement of clinical education in this regard.

\section{Data analysis}

Data analysis was performed in SPSS version 16 (SPSS Inc., Chicago, IL, USA). Attitude of nurses and its subscales were expressed as frequency and percentage. Moreover, Kolmogorov-Smirnov test was indicative of the normal distribution of data regarding the mean scores of attitude in nurses $(P=0.394)$. Parametric statistical tests, including Pearson's correlation-coefficient, Student's t-test, and one-way analysis of variance (ANOVA), were used to determine the correlations between the total score of attitude and variables such as age, marital status, ward of employment, and clinical experience. In all statistical analyses, $P$ value of less than 0.05 was considered significant.

\section{Results}

Out of 180 eligible nurses, 150 participants completed the questionnaires (response rate $=83.3 \%$ ). Mean age of the participants was $35.756 .75 \pm$ years, and the majority of the nurses were female ( $90 \%)$. In addition, most of the participants were employed as nurses (95.3\%), and the others were clinical supervisors. Mean clinical of experience of the participants was $12.507 .11 \pm$ years, and $80.7 \%$ were married.

The majority of nurses believed that nursing students acquired insufficient clinical experiences in the clinical environment. They mostly agreed with the items in subscales of time, background comparison, and personal issues, while they disagreed with the items in subscales of motivation, knowledge, and professional issues. Additionally, respondents were undecided about the items in the subscale of instructor-student relationship (Tables 1, 2 \& 3).

According to the results of this study, mean score of attitude in nurses was $86.04 \pm 10.94$ (range: $51-119$ ). In other words, the majority of our participants $(82 \%)$ had a negative attitude toward the attendance of nursing students in clinical settings.

Results of Student's t-test and Pearson's correlation-coefficient showed no significant

Table 1. Attitudes of nurses toward nursing students in terms of time, motivation, and professional relationship subscales in Hajar Hospital of Shahrekord, Iran (2015)

\begin{tabular}{|c|c|c|c|c|}
\hline Subscales & Items & Agree N (\%) & Undecided N (\%) & Disagree $\mathbf{N}(\%)$ \\
\hline \multirow{7}{*}{ Time } & $\begin{array}{l}\text { With nursing students who are new to the unit, nurses have more time } \\
\text { to perform other tasks. }\end{array}$ & $62(41.3)$ & $40(36.7)$ & $48(32)$ \\
\hline & $\begin{array}{l}\text { With nursing students who are familiar with the unit, nurses have more } \\
\text { time to perform other tasks. }\end{array}$ & $105(70)$ & $18(12)$ & $27(18)$ \\
\hline & There is too much to do to have to worry about nursing students. & $121(80.7)$ & $20(13.3)$ & $9(6)$ \\
\hline & Nursing students cause more trouble than help. & $30(20)$ & $68(45.3)$ & $52(34.7)$ \\
\hline & $\begin{array}{l}\text { I would not have to spend extra time with nursing students if the } \\
\text { instructor supervised their performance. }\end{array}$ & $117(78)$ & $23(15.3)$ & $10(6.7)$ \\
\hline & Nursing students have sufficient time to attend to the needs of patients. & $78(52)$ & $37(24.7)$ & $35(23.3)$ \\
\hline & Total & $85.5(56.66)$ & $34.33(22.88)$ & $30.16(20.10)$ \\
\hline \multirow{5}{*}{ Motivation } & Nursing students willingly help nursing staff to fulfill their duties. & $22(14.7)$ & $45(30)$ & $83(55.3)$ \\
\hline & Nursing students help other students to perform daily tasks. & $41(27.3)$ & $52(34.7)$ & $57(38)$ \\
\hline & Nursing students are enthusiastic to learn. & $37(24.7)$ & $48(32)$ & $65(43.3)$ \\
\hline & Nursing students do only what they are assigned. & $108(72)$ & $32(21.3)$ & $10(6.7)$ \\
\hline & Total & $52(35)$ & $44.25(29.5)$ & $53.75(35.83)$ \\
\hline \multirow{4}{*}{$\begin{array}{l}\text { Instructor-student } \\
\text { relationship }\end{array}$} & Nursing students are too intimate with instructors. & $39(26)$ & $46(30.7)$ & $65(43.3)$ \\
\hline & Nursing students often rely on instructors rather than nurses. & $86(57.3)$ & $49(32.7)$ & $15(10)$ \\
\hline & It is time instructors eased up on nursing students. & $37(24.7)$ & $69(46)$ & $44(29.3)$ \\
\hline & Total & $54(36)$ & $54.66(36.44)$ & $41.34(27.56)$ \\
\hline
\end{tabular}


Table 2. Attitudes of nurses toward nursing students in terms of professional issues and knowledge subscales in Hajar Hospital of Shahrekord, Iran (2015)

\begin{tabular}{|c|c|c|c|c|}
\hline Subscales & Items & Agree $N(\%)$ & Undecided N (\%) & Disagree $N(\%)$ \\
\hline \multirow{9}{*}{ Knowledge } & You cannot tell nursing students anything because they know everything. & $12(8)$ & $20(13.3)$ & 118 (78.7) \\
\hline & Nursing students ask too many questions. & $43(28.7)$ & $59(39.3)$ & $48(32)$ \\
\hline & Nurses learn new information from nursing students. & $22(14.7)$ & $40(26.7)$ & $88(58.7)$ \\
\hline & Today, nursing schools provide quality education. & $25(16.7)$ & $54(36)$ & $71(47.3)$ \\
\hline & Nursing students make hasty decisions quite often. & $36(24)$ & $85(56.7)$ & $29(19.3)$ \\
\hline & Nursing students ask good questions. & $38(25.3)$ & $54(36)$ & $58(38.7)$ \\
\hline & Nursing students seem to have no common sense. & $74(49.3)$ & $57(38)$ & $19(12.7)$ \\
\hline & Nursing students do not gain adequate clinical experience. & $99(66)$ & $32(21.3)$ & $19(12.7)$ \\
\hline & Total & $43.62(29.8)$ & $50.12(33.41)$ & $56.26(37.50)$ \\
\hline \multirow{7}{*}{$\begin{array}{l}\text { Professional } \\
\text { issues }\end{array}$} & I believe that nursing students respect nurses as practitioners. & $50(33.3)$ & $57(38)$ & $43(28.7)$ \\
\hline & Nurses consider nursing students as part of the nursing team. & $58(38.7)$ & $43(28.7)$ & $49(32.7)$ \\
\hline & Nurses should not have to do the teaching for which the clinical instructors are paid. & $71(47.33)$ & $35(23.34)$ & $44(29.33)$ \\
\hline & Nursing students are too intimate with the physicians. & $14(9.3)$ & $70(46.7)$ & $66(44)$ \\
\hline & Questions asked by nursing students encourage new ways of performing daily tasks. & $40(26.75)$ & $51(34)$ & $59(39.3)$ \\
\hline & Nursing students appear professional. & $16(10.7)$ & $38(25.3)$ & $96(64)$ \\
\hline & Total & $41.5(27.66)$ & $49(32.66)$ & $59.5(39.66)$ \\
\hline
\end{tabular}

associations between age, clinical experience, marital status, and attitude of nurses toward the attendance of nursing students in clinical settings
$(P>0.05)$. However, results of one-way ANOVA were indicative of a significant difference in terms of the ward of employment and attitude, as nurses

Table 3. Attitudes of nurses toward nursing students in terms of personal issues and background comparison subscales in Hajar Hospital of Shahrekord, Iran (2015)

\begin{tabular}{|c|c|c|c|c|}
\hline Subscales & Items & Agree N (\%) & Undecided N (\%) & Disagree $\mathbf{N}(\%)$ \\
\hline \multirow{7}{*}{$\begin{array}{l}\text { Background } \\
\text { comparison }\end{array}$} & We were all students once, so we should be tolerant with nursing students. & $116(77.3)$ & $27(18)$ & $7(4.7)$ \\
\hline & Baccalaureate nursing students are not as well prepared clinically as those with diploma. & $57(38)$ & $47(31.3)$ & $46(30.7)$ \\
\hline & Baccalaureate nursing students are not as well prepared clinically as students. & $58(38)$ & $49(32.7)$ & $43(28.7)$ \\
\hline & Baccalaureate nursing students are not as well prepared clinically as paramedic staffs. & $100(66.7)$ & $38(25.3)$ & $12(8)$ \\
\hline & I had it tough in nursing school, so current nursing students must do as well. & $119(79.3)$ & $25(16.7)$ & $6(4)$ \\
\hline & I would have never dreamed of calling my instructors by their first name. & $71(47.3)$ & $59(39.3)$ & $20(13.3)$ \\
\hline & Total & $86.83(57.88)$ & $40.83(27.22)$ & $22.33(14.88)$ \\
\hline \multirow{9}{*}{$\begin{array}{l}\text { Personal } \\
\text { issues }\end{array}$} & Nursing students accept constructive criticism. & $51(34)$ & $38(25.3)$ & $61(40.7)$ \\
\hline & $\begin{array}{l}\text { Nursing students become overwhelmed if they have to provide care for more than one } \\
\text { or two patients. }\end{array}$ & $71(47.3)$ & $41(27.3)$ & $38(25.3)$ \\
\hline & Nursing students are too dependent on the nursing staff. & $84(56)$ & $44(29.3)$ & $22(14.7)$ \\
\hline & Nursing students do not have enough self-confidence. & $94(62.7)$ & $45(30)$ & $11(7.3)$ \\
\hline & I enjoy working with nursing students. & $44(29.3)$ & $59(39.3)$ & $47(31.3)$ \\
\hline & Nursing students provide proper patient care. & $35(23.3)$ & $48(32)$ & $67(44.7)$ \\
\hline & Nursing students admit when they do not know something. & $42(28)$ & $55(36.7)$ & $53(35.3)$ \\
\hline & Nursing students practice assertiveness. & $20(13.3)$ & $54(36)$ & $76(50.7)$ \\
\hline & Total & $55.12(36.74)$ & $48(32)$ & $46.88(31.25)$ \\
\hline
\end{tabular}


engaged in the psychiatric ward had the most positive attitude, while NICU nurses had the most negative attitude toward this issue $(P=0.004)$.

Based on the viewpoints of the nurses who replied to the open questions $(n=40)$, negative aspects of the attendance of nursing students in clinical settings were overcrowding ( $80 \%$ ), challenges and conflicts between nurses and students (68.2\%), failure to perform the assigned tasks properly $(72.3 \%)$, increased risk of medical errors $(38.2 \%)$, and patient dissatisfaction (45.8\%).

On the other hand, nurses believed that students could help with preparing nursing reports (82.3\%), patient transfer $(53.2 \%)$, and communication with patients $(89.2 \%)$. Furthermore, they assumed that improvement of clinical education is possible by adopting effectual strategies. Such examples were increasing the supervision of instructors (62.4\%), recruitment of clinical experts as instructors $(88.2 \%)$, effective interactions between clinical nurses and instructors (68.2\%), decreasing the ratio of students $(65.3 \%)$, raising the awareness of community members toward nursing roles $(32.8 \%)$, promoting the communication skills of nursing students $(92.8 \%)$, motivating instructors $(40 \%)$, motivating nursing students $(92.3 \%)$, and providing adequate learning opportunities (48.9\%).

\section{Discussion}

In In the present study, the majority of nurses had a negative attitude toward the attendance of nursing students in clinical settings. Nursing is a practical discipline, in which students must be present in clinical settings in order to cooperate with nurses in the provision of patient care (11). Therefore, attitudes of nurses and nursing students toward each other remarkably influence the promotion of clinical learning (12).

According to the results of the current study, nurses mostly feel ambivalent toward nursing students (13). As mentioned by our participants, this could be attributed to different factors, such as overcrowding due to the presence of students in hospital wards, challenges between nurses and students, and concerns regarding the tasks performed by nursing students (e.g., possibility of medical errors).

Similar to previous studies in this regard, the majority of our participants agreed that they had to be kind and tolerant with nursing students since they were once students as well $(3,14)$; nevertheless, they had a negative attitude toward the attendance of nursing students in clinical settings. Furthermore, the majority of our participants believed that nursing students gained insufficient clinical experiences in clinical environments. It is also noteworthy that despite the healthcare measures performed by nursing students or their instructors, nurses are responsible for care provision under most circumstances (15).

Findings of the current study were indicative of a significant difference between the ward of employment and attitude of nurses toward the attendance of nursing students in the clinical setting. Accordingly, nurses engaged in the psychiatric ward had the most positive attitude, whereas NICU nurses showed the most negative attitude in this regard. Furthermore, psychiatric ward nurses confirmed that students greatly helped with preparing nursing reports, patient transfer, and communication with patients. However, appropriate patient care requires specialty and adequate experience in some wards (e.g., NICU), which could not be fulfilled by nursing students. Therefore, their attendance in these sections yielded no benefits for nurses.

In the present study, the majority of nurses believed that they had so many duties that they could not worry about nursing students, which denotes the negative attitude of nurses toward the attendance of nursing students. This is in congruence with the results of another study conducted in Iran (3).

According to the findings of the current research, the majority of nurses believed that in the presence of supervising instructors, they would not have to spend extra time with nursing students since clinical instructors are paid to do the teaching for students. In a review study in this regard, lack of clinical instructors and inadequate facilities were determined as two major clinical learning problems (16).

In a similar research, working with practicing faculty members was reported to cause higher role overload, conflict and ambiguity compared 
to working with non-practicing faculty members (15). In the present study, nurses believed that improvement of clinical education is possible through adopting effectual strategies, such as increasing the supervision of instructors, recruitment of expert clinical instructors, and promoting collaborations between healthcare centers and universities. These findings emphasize on the key role of instructors in enhancing the quality of clinical education and reducing deficiencies in this area.

In the current study, the majority of nurses believed that nursing students mainly attend to the assigned tasks and rarely help nurses willingly. As such, one of the main reasons for attrition among nurses was reported to be the negative attitudes of healthcare team members and inappropriate clinical environment (17). These findings could be attributed to the motivational deficiency and displeasure of nursing students in the clinical environment. In this respect, our participants presumed that quality of clinical learning could increase through the enhancement of communication skills and motivation of nursing students and instructors. Findings of a research performed in Iran suggested that the communication skills of senior nursing students are at a moderate level (18).

Poor interpersonal communication between nurses and nursing students adversely affects clinical learning (19). Collaboration in collegial relationships is considered essential to proper learning and socialization in the nursing profession (2). Providing a supportive environment and efficient communication between nurses and nursing students could promote learning, increase motivation, and emphasize on the importance of these skills (20). Moreover, supportive behaviors on behalf of nurses are crucial in the development of communication skills in nursing students (21).

In the present study, the majority of participants agreed that nursing students tend to rely on their instructors rather than nurses. In addition, attitudes of nurses toward the assertiveness of nursing students in clinical practice were mostly negative, and they believed that nursing students lack adequate self-confidence. This could be due to the variable personality traits of nursing students, as well as the collaborative gap between universities and healthcare centers.

High student-teacher ratio may lead to the inability of instructors in conveying necessary learning skills. Since the constant presence of instructors in the clinical environment is not possible, acquirement of professional skills from nurses seems to be of paramount importance (15). Therefore, instructors must clarify the role of nurses in clinical learning for nursing students, especially during internship.

In the current research, the majority of nurses believed that education used to be discipline-based in the past, with nursing students interacting with instructors conservatively. However, adoption of new educational methods today has changed this pattern. Nursing instructors are aware of the emotions of students, which obliges them to promote positive attitudes in the clinical environment in order to facilitate learning (22).

On the other hand, nurses in the present study believed that nursing students fail to gain sufficient clinical experience, lack professionalism, and need to be reminded of the acquired knowledge. Moreover, it was emphasized that in the past, nursing students would obtain more clinical experiences compared to nursing students today. This is in line with the results of another study conducted in Iran, in which nurses claimed that nursing students do not develop sufficient clinical skills by attending clinical settings (3).

Professional skills of nursing students are a major influential factor for patient satisfaction (18). In a similar study performed in Iran, most nursing students could not obtain the desired skills in nursing practice. In another research, knowledge and skills of nursing students were reported to be at an acceptable level, whereas their abilities in patient education were relatively poor $(18,23)$.

One of the limitations of the present study was the small sample size. Additionally, some of our participants did not complete the questionnaires and mostly responded to the open questions.

\section{Conclusion}

In their profession, nurses are under tremendous 
stress due to different factors, such as staff shortage, heavy workload and continuous patient care. Nurses are required to cooperate with nursing students even without satisfaction. As such, nursing managers must provide a supportive environment for educational interventions and assessment of the attitudes of nurses toward these students, emphasizing on the proper interaction between nurses and clinical instructors. Promotion of the attitudes of nurses and nursing students toward clinical education could facilitate learning, create diversity in clinical opportunities, provide adequate equipment, and provide sufficient time for performing care procedures.

\section{Conflicts of interest}

None declared.

\section{Authors' contributions}

N. Parvin: project advisor, study design; F. Aliakbari, L. Rafiee: data collection; N. Dadkhah: data analysis; L. M. Jouybari: advisor on scientific development, validation of questionnaires. All authors contributed equally to the review, revision, editing and drafting of the manuscript.

\section{Acknowledgments}

Hereby, we extend our gratitude to all the nurses who participated in this study. This research project was financially supported by Shahrekord University of Medical Sciences, Iran (grant number: 1898).

\section{References}

1. Tomietto M, Comparcini D, Simonetti V, Pelusi G, Troiani $\mathrm{S}$, Saarikoski M, et al. Work-engaged nurses for a better clinical learning environment: a ward-level analysis. J Nurs Manag 2015; 24(4):475-82.

2. Atack L, Comacu M, Kenny R, LaBelle N, Miller D. Student and staff relationships in a clinical practice model: impact on learning. J Nurs Educ 2000; 39(9):387-92.

3. Aghamohammadi-Kalkhoran M, Karimollahi M, Abdi R. Iranian staff nurses' attitudes toward nursing students. Nurse Educ Today 2011; 31(5):477-81 (Persian).

4. Flott EA, Linden L. The clinical learning environment in nursing education: a concept analysis. J Adv Nurs 2016; 72(3):501-13.

5. Levett-Jones $\mathrm{T}$, Lathlean J, Higgins I, McMillan M. Staff-student relationships and their impact on nursing students' belongingnes and learning. J Adv Nurs 2009; 65(2):316-24.

6. Sedgwick MG, Rougeau J. Points of tension: a qualitative descriptive study of significant events that influence undergraduate nursing students' sense of belonging. Rural Remote Health 2010; 10(4):1569.

7. Dunn SV, Hansford B. Undergraduate nursing students' perceptions of their clinical learning environment. J Adv Nurs 1997; 25(6):1299-306.

8. Vallant $\mathrm{S}$, Neville $\mathrm{S}$. The relationships between student nurse and nurse clinician: impact on student learning. Nurs Prax N Z 2006; 22(3):23-33.

9. Hathorn D, Machtmes K, Tillman K. The lived experience of nurses working with student nurses in the clinical environment. Qualitat Rep 2009; 14(2):227-44.

10. Stagg SJ. Staff nurses attitudes toward nursing students. [Master Thesis]. Salisbury, USA: Salisbury State University; 1992.

11. Slaughter-Smith C, Helms JE, Burris R. Nursing staff perceptions of student contributions in clinical settings. J Nurs Educ 2012; 51(1):54-7.

12. Chuan OL, Barnett T. Student, tutor and staff nurse perceptions of the clinical learning environment. Nurse Educ Pract 2012; 12(4):192-7.

13. Matsumura G, Callister LC, Palmer S, Cox AH, Larsen L. Staff nurse perceptions of the contributions of students to clinical agencies. Nurs Educ Perspect 2004; 25(6):297-303.

14. Jackson J, Neighbors M. A study of nurses' attitudes towards associate degree nursing students. J Adv Nurs 1988; 13(3):405-9.

15. Langan JC. Faculty practice and roles of staff nurses and clinical faculty in nursing student learning. J Prof Nurs 2003; 19(2):76-84.

16. Pazokian M, Rassouli M. Challenges of nursing clinical education in the world. J Med Educ Dev 2012; 5(8):18-26 (Persian).

17. Joolaee S, Mehrdad N, Bohrani N. A survey on nursing students' opinions toward nursing and reasons for giving it up. Iran J Nurs Res 2006; 1(1):21-8 (Persian).

18. Negarandeh R, Mohammadi S, Zabolypour S, Arazi Ghojegh T. Relationship between quality of senior nursing students' caring behaviors and patients' satisfaction. J Hayat 2012; 18(3):10-21 (Persian).

19. Mabuda BT, Potgieter E, Alberts UU. Student nurses' experiences during clinical practice in the Limpopo Province. Curationis 2008; 31(1):19-27.

20. Hanifi N. Nurses as motivators or suppressors of nursing students' learning in clinical learning. J Nurs Educ 2012; 1(1):14-24 (Persian).

21. White AH. Clinical decision making among fourth-year 
nursing students: an interpretive study. J Nurs Educ 2003; 42(3):113-20.

22. Reeve KL, Shumaker CJ, Yearwood EL, Crowell NA, Riley JB. Perceived stress and social support in undergraduate nursing students' educational experiences. Nurse Educ
Today 2013; 33(4):419-24.

23. Roghani PS, Akbarsharifi T, Ruzbeh F, Shekarabi R, Haghani H. A study of senior nursing student's opinions about clinical skills level acquired during nursing training. Iran J Nurs 2006; 18(44):67-76 (Persian). 